\title{
Ontigo e o moderno na teoria literária de Friedrich Schlegel no Primeiro Romantismo Alemão
}

The ancient and the modern in Friedrich Schlegel's literary theory in the Early German Romanticism http://dx.doi.org/10.11606/1982-88372032136

\section{Constantino Luz de Medeiros ${ }^{1}$}

\begin{abstract}
The historical understanding of literature in German Early Romanticism arises, among other things, from the writings of Winckelmann, Herder, Lessing as well as of the dialectical interplay between classic and romantic established by Goethe and Schiller. In this context, the antithetic approximation of ancient and modern plays a central role in the determination of the major romantic theories of literature. This paper investigates and discusses the importance of the antinomy of ancient and modern in the constitution and development of literary theories of Friedrich Schlegel in German Early Romanticism.
\end{abstract}

Keywords: Ancient and modern, classical and romantic, Early German Romanticism, Friedrich Schlegel, history of literary criticism

Resumo: A compreensão histórica de literatura no primeiro romantismo alemão decorre, entre outros aspectos, dos escritos de Winckelmann, Herder, Lessing, assim como da relação dialética entre o clássico e o romântico estabelecida por Goethe e Schiller. Nesse contexto, a aproximação antitética entre o antigo e o romântico tem um papel central na determinação das principais teorias românticas de literatura. $\mathrm{O}$ artigo investiga e discute a importância da antinomia entre o antigo e o moderno na constituição e desenvolvimento das teorias literárias de Friedrich Schlegel no primeiro romantismo alemão.

Palavras-chave: Antigo e moderno, clássico e romântico, primeiro romantismo alemão, Friedrich Schlegel, história da crítica literária

\section{Introdução}

A consciência histórica sobre a antinomia entre as épocas da poesia, ou seja, a noção da diferença entre a poesia dos antigos e dos modernos é um dos pilares da teoria de

\footnotetext{
${ }^{1}$ Universidade Federal de Minas Gerais, Faculdade de Letras, Av. Antônio Carlos, 6627, Belo Horizonte, MG, 31270-901, Brasil. E-mail: constanteluz@gmail.com
} 


\section{Medeiros, C. L. - O antigo e o moderno na teoria literária de F. Schlegel}

literatura do primeiro romantismo alemão. Essa percepção histórica sobre a literatura fundamenta grande parte dos escritos, teorias e temas do movimento romântico de Iena. É possível contemplar essa dialética na maioria das criações de Friedrich Schlegel e de seu irmão August Wilhelm Schlegel. As revistas que publicam entre os anos 1798 e 1801 (Athenäum, Lyceum), bem como suas obras teóricas e romances são fruto da ação recíproca (Wechselwirkung) entre o antigo e o moderno. A ironia romântica de Schlegel, ${ }^{2}$ por exemplo, surge a partir da junção de termos da tradição filosófica e literária, tais como a ironia socrática, a parábase do coro grego, aos quais o pensador aproxima fenômenos de seu tempo. A combinação entre o antigo e moderno atravessa igualmente a crítica e a criação literária dos românticos. Suas obras revelam não apenas o imenso respeito e admiração pela Antiguidade, mas a busca pela aproximação entre esses dois mundos.

A delimitação entre as épocas da arte literária realizada por Schlegel em textos como o Über das Studium der griechischen Poesie ("Sobre o estudo da poesia grega"), publicado em 1795, quase que concomitantemente aos ensaios de Schiller sobre o poeta ingênuo e sentimental, não teria sido possível sem o seu conhecimento histórico e a clara delimitação do que era a poesia dos antigos e a dos modernos (SCHLEGEL 1979: 217). ${ }^{3}$ Uma das premissas mais importantes do pensamento crítico-literário de Friedrich Schlegel é o conhecimento histórico das épocas da poesia, ou seja, a certeza de que "não podemos conhecer o clássico sem o progressivo" (SCHLEGEL 2016: 18). De modo semelhante ao que Johann Joachim WinCKELMANN (1717-1768) postulara no campo das artes visuais, SCHLEGEL (1979: 39) indica que havia quatro escolas principais da poesia entre os gregos, a jônica, a dória, a ateniense e a alexandrina e que a arte helênica atingiu o grau máximo de perfeição ao atravessar todos os ciclos de sua formação natural: nascimento, desenvolvimento, plenitude e declínio. Entre os gregos, a poesia havia encontrado a perfeição e o acabamento. Já no caso da época moderna, a arte literária se caracteriza por pertencer ao sistema progressivo da formação artificial, na qual a perfeição completa é apenas um ideal que jamais pode se concretizar, porque toda vez que um máximo relativo é atingido uma nova fase é instaurada (SCHLEGEL 1979: 288). A compreensão histórica de literatura no primeiro romantismo alemão decorre, entre outros aspectos, dos escritos de Winckelmann, Herder, Lessing, assim

\footnotetext{
${ }^{2}$ Quando referido apenas pelo sobrenome trata-se de Friedrich Schlegel.

${ }^{3} \mathrm{O}$ escrito Über das Studium der griechischen Poesie, também conhecido como Studium-Aufsatz, foi iniciado em 1795, e publicado parcialmente na revista Deutschland, (Alemanha), em 1796.
} 


\section{Medeiros, C. L. - O antigo e o moderno na teoria literária de F. Schlegel}

como da relação dialética entre os modos clássico e o romântico de sentir e de atuar no campo literário, estabelecidos por Goethe e Schiller. Nesse contexto, a aproximação antitética entre o clássico e o romântico tem um papel central na determinação das principais teorias românticas de literatura. $\mathrm{O}$ artigo investiga e discute a importância da antinomia entre o antigo e o moderno na constituição e desenvolvimento das teorias literárias de Friedrich Schlegel no primeiro romantismo alemão.

\section{A herança de Winckelmann}

O espírito de toda a minha poesia parece ser a harmonia entre o antigo e o moderno (SCHLEGEL 2016: 368).

Ainda na década de 1770, Johann Gottfried HeRDER (1985: 310) questionava onde se encontrava o Winckelmann da poesia alemã, um estudioso capaz de realizar no âmbito da literatura aquilo que Johann Joachim WINCKELMANN (1717-1768) fizera pela escultura antiga, estabelecendo as leis de seu desenvolvimento histórico. A questão levantada por Herder encontrará resposta nos estudos e pesquisas de Friedrich Schlegel sobre a literatura dos antigos e dos modernos. Desde então, diversos estudiosos indicam que Schlegel realmente cumpriu a profética sentença herderiana. Rudolf Haym, em sua Escola romântica (1870), apontou para a perícia com que o jovem Friedrich Schlegel fundamentou sua perspectiva histórica da literatura, buscando conceituar a relação entre a poesia dos modernos e a dos antigos em seus diversos ensaios. De acordo com o autor da Escola romântica, Schlegel elevara os gregos ao Absoluto. Para Haym, assim como surgiu um Winckelmann da arte em Roma, deveria aparecer um estudioso da poesia na Alemanha (HAYM 1977: 179). Mesmo Heinrich Heine, crítico contumaz dos românticos de Iena, elogia os estudos e pesquisas sobre a Antiguidade clássica de Schlegel, e sua formidável facilidade em aprender línguas, como o grego, o persa e o sânscrito (HEINE 1997: 307). A admiração que o jovem romântico nutria por Winckelmann foi motivada, sobretudo, pela consciência histórica que fundamentava suas considerações sobre a arte antiga, e que o inspiraram na resolução da problemática entre os períodos da poesia. Anos mais tarde, no prefácio de suas obras completas publicadas em 1823, o estudioso recorda-se do tempo de sua juventude, e do papel de Winckelmann em sua formação: 


\section{Medeiros, C. L. - O antigo e o moderno na teoria literária de F. Schlegel}

Nos primeiros anos da juventude, com aproximadamente 17 anos, os escritos de Platão, os poetas trágicos gregos, e as entusiásticas obras de Winckelmann formaram meu mundo espiritual, e o ambiente onde eu vivia [...] em minha solidão poética reflexiva, embora ainda em um estilo juvenil, eu tentava modelar na alma as ideias e figuras dos antigos deuses e heróis (SCHLEGEL 1979: 44).

O conhecimento de Schlegel sobre a literatura greco-romana se intensificou com sua estadia em Dresden, entre os anos 1794 e 1796, quando o pensador, com o auxílio e a proteção de sua irmã Charlotte Schlegel, pôde desfrutar do tempo e da tranquilidade de espírito necessários ao estudo detalhado da Antiguidade (ZIMMERMANN 2009: 3). De fato, nos dois anos que permaneceu em Dresden, ele não apenas fez um estudo detalhado da poesia greco-romana, mas também fundamentou sua teoria crítico-literária, a qual serviu de base para diversas concepções do primeiro romantismo alemão. Em sua busca pela aproximação entre as épocas da poesia, Schlegel observa a organização dos fenômenos da literatura em seu movimento histórico, definindo a poesia grega como uma poesia natural (Naturpoesie), cujo desenvolvimento segue o ritmo cíclico de nascimento, crescimento, auge e declínio (SCHLEGEL 1979: 275). A poesia moderna, ao contrário, era considerada por Schlegel como uma poesia artificial (Kunstpoesie), isto é, o fruto do entendimento e da razão, cujo movimento obedecia a uma progressão infinita. Essa cadeia de evoluções, ou revoluções, que a literatura moderna apresenta, seria o resultado não de um desenvolvimento natural e espontâneo, como na Antiguidade, mas o fruto da razão e da criatividade do espírito (SCHLEGEL 1979: 276). Apesar de se mover em uma progressividade infinita, a poesia interessante (no sentido de reflexiva) dos modernos era limitada por aquilo que Schlegel denominaria de maximum absoluto, o que significa que a cada grau máximo de perfeição uma nova série se iniciava.

Ao afirmar que Winckelmann foi o primeiro a sentir a antinomia entre o antigo e o moderno e que o historicismo winckelmanniano seria o melhor caminho para uma filosofia da filologia, Schlegel almejava fundamentar sua concepção de que os âmbitos separados da crítica, da teoria, da história, da filosofia, da filologia e da arte deviam se unificar. $\mathrm{O}$ autor das Reflexões sobre a arte antiga acreditava que na Antiguidade a exteriorização artística começara com as figuras mais simples, onde a forma e o conteúdo ainda se conservavam muito próximos. Com o gradativo desenvolvimento, a arte passa a ser cada vez mais sofisticada, até atingir seu ápice e ser teorizada por estudiosos, para depois perder-se em artifícios e adereços desnecessários, desaparecendo com o passar do tempo (WINCKELMANN 1934: 26). A mesma lógica 
Medeiros, C. L. - O antigo e o moderno na teoria literária de F. Schlegel

winckelmanniana é seguida em seu escrito Von den Schulen der griechischen Poesie ("Sobre as escolas da poesia grega"), de 1794, no qual Schlegel descreve o desenvolvimento das diferentes escolas da poesia grega: a jônica, a dórica, a ateniense e, por último, a alexandrina (SCHLEGEL 1979: 5). Nesse sentido, a decadência da arte literária grega foi o resultado de um processo ou ciclo natural, como os fenômenos biológicos da natureza. Após ter alcançado a perfeição da organização de suas partes e a harmonia do conjunto, a poesia grega enveredou pela trilha do desnecessário e do acessório, perdendo-se em exercícios retóricos na poesia alexandrina (SCHLEGEL 1979: 17). Os escritos sobre a Antiguidade clássica de Schlegel ecoam muitos preceitos de Winckelmann, como a ideia de que a história da arte deve expor toda a sequência de seu desenvolvimento orgânico, e que mesmo as diferenças entre os mais diversos estilos e povos precisam ser deduzidas da própria história, a partir daquelas obras que restaram da Antiguidade (WINCKELMANN 1934: 26). No primeiro de seus Fragmentos sobre poesia e literatura, escritos entre os anos 1797 e 1803, é possível perceber esse entusiasmo de Schlegel por Winckelmann:

A diferença entre o clássico e o progressivo é de origem histórica, por isso ela está ausente na maioria dos filólogos. Tam bém nesse aspecto, com Winckelmann começa uma época inteiramente nova. Meu mestre. Ele viu a diferença imensurável, a natureza toda própria da Antiguidade. No fundo, permaneceu sem seguidores (SCHLEGEL 2016: 9).

Como Winckelmann, Schlegel acreditava que uma história natural da arte e do gosto deve levar em consideração "o desenvolvimento histórico da poesia, seu caráter, as relações entre as diversas épocas, as razões para sua aparição, seu auge, seu declínio" (SCHLEGEL 1979: 305). A inspiração para o estabelecimento da história da literatura europeia, desde as origens gregas até a época romântica, advém de Winckelmann, o precursor de uma visão histórica sobre o conjunto da arte grega. A partir da constatação de que Winckelmann estabelecera uma doutrina material da Antiguidade, restava então aos modernos, de acordo com Schlegel, ter a clareza da diferença fundamental entre os antigos e os modernos. Para Ernst BEHLER (1992: 120), esse seria o primeiro passo no caminho da constituição de uma nova ciência da literatura:

O sistemático Winckelmann, que, por assim dizer, lia todos os antigos como um único autor, via tudo no todo e concentrava toda a sua força nos gregos, estabeleceu, pela percepção da diferença absoluta entre o antigo e o moderno, o primeiro fundamento de uma doutrina material da Antiguidade. Somente quando forem encontrados o ponto de vista e as condições da identidade absoluta que existiu, existe ou existirá entre o antigo 


\section{Medeiros, C. L. - O antigo e o moderno na teoria literária de F. Schlegel}

e o moderno, se poderá dizer que ao menos o contorno da ciência está pronto, e agora se poderá pensar na execução metódica (SCHLEGEL 1997: 71).

Schlegel concorda com a posição de Winckelmann sobre aquilo que diferenciava a arte dos antigos e dos modernos, mas suas posições diferem quanto à valorização de cada uma dessas épocas. Enquanto para o autor das Reflexões sobre a arte antiga, por ser infinitamente inferior, a arte moderna deveria apenas emular a arte grega, Schlegel busca a aproximação recíproca entre essas duas épocas da poesia, pois acreditava que a literatura de seu tempo - em sua ênfase no subjetivo e no reflexivo - seria o caminho para uma literatura em devir. Como o crítico assevera, "o horror de Winckelmann pela modernidade só pode ser explicado por seu sentido para o clássico, pois isso ele possuía em alto grau, bem mais que os outros, transformando tudo em clássico" (SCHLEGEL 2016: 67). Em sua História da arte da Antiguidade, WinCKELMANN (1934: 171) reconhece quatro períodos da antiga escultura grega: “o grande e alto estilo dos primeiros tempos; o belo auge da era de Péricles; o declínio com os imitadores; o fim com os últimos maneiristas helênicos”. Nessa concepção, a bela arte grega, compreendida principalmente como a perfeição dos corpos na estatuária, havia se desenvolvido livremente a partir da espontaneidade da natureza, de forma orgânica. A beleza ideal nas formas gregas é o resultado feliz dessa natureza propícia.

As metáforas relacionadas aos estágios da vida orgânica, utilizadas com frequência pelo estudioso, são transferidas para o âmbito da arte, passando a descrever as fases da escultura grega. Ao indicar que os modernos devem imitar os antigos se quiserem se tornar perfeitos, Winckelmann parte de conceitos de perfeição e de beleza nos quais é possível reconhecer elementos como o neoclassicismo platonizante, certos traços de virtude estoica, historicismo e forte sensualismo. De acordo com René Wellek, “o neoclassicismo de Winckelmann será retomado por Lessing, Goethe e Schiller, o sensualismo por Herder e pelo romancista Wilhelm Heinse, e o historicismo por Herder e pelos Schlegel” (WELlEK 1967: 136). Apesar das diferenças no que tange à poesia moderna, os irmãos Schlegel reconhecem o lugar que Winckelmann ocupa e sua influência no estabelecimento dos estudos sobre a Antiguidade clássica na Alemanha; August Wilhelm chega a denominá-lo de "o verdadeiro fundador da história da arte" (SCHLEGEL 1963: 24). Ao embasar grande parte de suas teorias literárias na antinomia entre o antigo e o moderno, Schlegel foi capaz de deduzir o ponto de inflexão entre as duas épocas da poesia. A conciliação entre os dois âmbitos da poesia foi realizada pelo 


\title{
Medeiros, C. L. - O antigo e o moderno na teoria literária de F. Schlegel
}

estudioso de um modo peculiar através do conceito de poesia romântica, universal e progressiva; uma literatura em devir, na qual se aproximariam a objetividade da arte antiga e o caráter reflexivo da arte moderna. Como seu mestre, o sistemático Winckelmann, aquele que reconheceu a distância imensurável entre a arte dos antigos e a dos modernos, Schlegel também aproximou as épocas da poesia através de seu conceito de poesia romântica.

\section{A filosofia da filologia de Friedrich Schlegel}

\author{
Os cantos homéricos existiram por séculos, \\ separados, em cantos divulgados pelos \\ aedos das diferentes escolas de arte, até que \\ foram colecionados e arranjados pelos \\ diaskeuastas (SCHLEGEL 1979: 511).
}

Outro âmbito no qual o estabelecimento da antinomia entre o antigo e o moderno tornase essencial é a crítica de literatura, também denominada por Schlegel de filosofia da filologia. Inspirado nas investigações filológicas de Friedrich August Wolf sobre a épica de Homero, e a publicação da obra Prolegomena ad Homerum (1795), Schlegel desenvolve a concepção de que a crítica literária e o trabalho filológico são instrumentos imprescindíveis para a completude e o aperfeiçoamento da própria literatura. Propondo uma exegese crítico-literária que aproxime a reflexão filosófica, a crítica e o estudo histórico da literatura, o estudioso indica que "o verdadeiro lugar da crítica é a filologia" (SCHLEGEL 2016: 52). Essa afirmação remete ao encontro inusitado da filosofia com a filologia no pensamento de Friedrich Schlegel, ou seja, a aproximação entre sua visão histórica dos fenômenos literários herdada de Winckelmann e Herder, a seriedade filológica no trato dos textos e manuscritos originária da escola de Wolf, e a filosofia de Fichte. Através do contato com a obra filológica dos antigos estudiosos de Alexandria, os denominados diaskeuastas, o autor do Studium-Aufsatz desenvolve a concepção de que o exercício de crítica literária deve ser uma tarefa infinita. Em sua origem, o termo diaskeuase faz referência aos estudiosos do período alexandrino, quando aqueles que tinham por atividade o estudo da literatura e a reposição dos textos homéricos apesar de atenderem pelo nome de gramáticos e críticos eram também chamados de diaskeuastas. Nesse sentido, a $\Delta \iota \alpha \sigma \kappa \varepsilon v \eta ́$ 


\title{
Medeiros, C. L. - O antigo e o moderno na teoria literária de F. Schlegel
}

(diaskeuase) significa a "ação de construir, organizar, pôr em ordem, revestir, disfarçar alguém com vestes, preparar uma pessoa para ação ou guerra, revestir com ornamentos ou apetrechos, e manipular medicamentos" (NEves; DezotTi; MalHadas 2010: 338). O termo também designa a organização para a guerra, para a ação, sendo tomado, mais tarde como a organização e crítica textual:

\begin{abstract}
Os nomes diaskeuastas e diaskeuase foram utilizados principalmente pelos críticos de Alexandria para denominar os antecessores que se ocuparam com a crítica textual de Homero. Incumbidos da organização do texto homérico por Pisístrato (605-527 a. C.) e seu filho Hiparco (550-490 a. C.) [ambos governantes de Atenas], entre esses eruditos encontrava-se Onomacrito de Atenas, Orfeu de Crotona, Zófiro, de Heraclea, entre outros. Os diaskeuastas assinalam o início da filologia grega. Por sua imensa contribuição para a história intelectual, através do estabelecimento da primeira crítica textual científica, seu nome é frequentemente utilizado por Schlegel também em um sentido figurado. Nessa acepção simbólica eles são até mesmo um conceito central de sua poética e de sua filosofia da cultura (BEHLER 1958: 288).
\end{abstract}

Dessa maneira, a concepção de diaskeuase pode ser entendida como uma eterna transformação da obra de arte literária, no sentido que lhe emprestara Goethe, em seu escrito Sobre a metamorfose das plantas, ou seja, como a infinita mutação de formas no âmbito da natureza. Alguns estudiosos levantam a hipótese de que Schlegel teria estudado as teorias naturais de Goethe e as inserido em seus escritos sobre a Antiguidade clássica (BENNE; BREUER 2011: 57). Enquanto tarefa interminável, a crítica também equivale a uma eterna metamorfose da obra. Como afirma Ernst BEHLER (1956: XIII), Schlegel foi igualmente um organizador, um compilador, portanto, um diaskeuasta. Em decorrência de suas investigações sobre a obra dos kritikoi de Alexandria, o estudioso desenvolve a concepção de que a obra de arte literária não pode prescindir do trabalho crítico como forma de sua complementação e acabamento. A descrição da atividade dos diaskeuastas de Alexandria surge já nos primeiros escritos de Schlegel. Nesses textos, o crítico afirma que, "embora a poesia homérica tenha sido diaskeuasiada, não se sabe ao certo o que os diaskeuastas poderiam ou não fazer com os cantos de Homero" (SCHLEGEl 1979: 517). A crítica dos diaskeuastas, e sua importância para o estabelecimento do texto homérico na Grécia Antiga faz com que o estudioso considere a diaskeuase imprescindível para a relação da crítica de literatura com a obra de arte literária. Na obra Geschichte der Poesie der Griechen und Römer, ("História da poesia dos gregos e romanos"), de 1796, Schlegel descreve como foram estabelecidos os cantos homéricos a partir do trabalho dos denominados diaskeuastas: 
Medeiros, C. L. - O antigo e o moderno na teoria literária de F. Schlegel

Como fonte do que descreverei se encontra a obra de Friedrich August Wolf, Prolegomena ad Homerum, que nos trouxe uma luz sobre a antiga poesia helênica. Os trabalhos de Wolf podem ser considerados originais e importantes por haver demonstrado que os cantos homéricos, antes espalhados em cantos individuais e singulares, foram coletados, rearranjados, editados e organizados pelos denominados diaskeuastas, no que agora se conhece como a Odisseia e a Iíada [...] Os cantos homéricos existiram por séculos, separados, em cantos divulgados pelos aedos das diferentes escolas de arte, até que foram colecionados e arranjados pelos diaskeuastas (SCHLEGEL 1979: 510).

Assim, o autor de Lucinde parte dos estudos dos diaskeuastas para o estabelecimento de uma crítica literária que complemente a obra artística, em uma atividade infinita e progressiva. A tarefa de reposição da obra de arte literária representada pela diaskeuase é também transferida do âmbito da crítica literária e da filologia para outras esferas da vida, passando a definir a atividade reflexiva em geral. Como faz com outros termos da tradição literária, o estudioso recupera o conceito de diaskeuase, transformando-o em metáfora de prática textual, criatividade crítico-literária, reflexão filológica e criação literária em segunda potência. Da mesma forma que os antigos diaskeuastas, muitas vezes o crítico literário deve buscar em sua exegese reestabelecer o sentido do texto. Através da arte crítico-literária dos diaskeuastas modernos, representada pela busca incessante de aperfeiçoamento da obra literária - por meio de uma crítica literária que leva em consideração o detalhe filológico, a percepção histórica, e a relação entre o espírito e a letra dos textos - Schlegel aponta para os fundamentos de uma ciência da crítica literária, no sentido moderno do termo, como apenas foi estabelecida muitos anos após sua morte. Ernst Robert Curtius assevera a importância da crítica literária de Schlegel para a história da literatura, principalmente por sua tentativa de aproximação dos âmbitos da crítica, da história e da teoria (CURTIUS 1996: 48).

Ao transferir o conceito de diaskeuase do âmbito da filologia e dos estudos de literatura para outros campos do saber, transformando-o em metáfora de atividade infinita, Schlegel recupera para a crítica literária a noção de restabelecimento e reposição do texto literário. As atividades de interpretação, complementação e restabelecimento da obra se transformam em um processo que se assemelha à reflexão potenciada de Fichte, ou seja, "um pensar sobre o pensar", de modo que "a reflexão se estende sem limites". Mais tarde, Walter Benjamin capta a apropriação e utilização que Schlegel faz do conceito de reflexão na filosofia de Fichte e sua inserção em sua crítica de literatura, afirmando que "o pensar do pensar como esquema originário de toda reflexão também está na base da concepção crítica de Schlegel” (BENJAMIN 2011: 48). 


\section{Medeiros, C. L. - O antigo e o moderno na teoria literária de F. Schlegel}

Assim como os antigos críticos de Alexandria, os quais buscaram diminuir a distância incomensurável entre sua época e a de Homero, a crítica literária de Friedrich Schlegel procura aproximar os âmbitos da poesia e da filosofia, outrora unificados, em uma crítica poética, filosófica, filológica, divinatória e genial. Nessa tarefa infinita, o papel do crítico de literatura é contribuir para que o diálogo entre o autor, a obra e o leitor seja intensificado. Walter Benjamin foi um dos primeiros críticos modernos a identificar esse processo, e a importância que a crítica assume no primeiro romantismo. De acordo com BENJAMIN (2011: 48), se arte representa o medium-de-reflexão, a crítica nada mais significa que a elevação e potenciação da obra de arte, o locus privilegiado de contemplação das determinações do espírito, e o instrumento de reflexão sobre a arte e a própria crítica. Desse modo, a tarefa infinita do crítico enquanto um diaskeuasta moderno se aproxima do trabalho realizado pelos antigos críticos, cujo método Schlegel descreve:

\footnotetext{
Mesmo depois que a era dos grandes poetas acabou, o sentido para a poesia não pereceu de todo. Em decorrência da grande quantidade de monumentos escritos que permaneceram, graças em parte à sua curiosidade e a um extenso amor, logo surgiu uma ciência para conhecer todas essas obras, o que não seria possível sem uma organização definida [...] uma ocupação que deveria preencher as lacunas dos antigos manuscritos, comparando diferentes versões [...] O método de seu estudo era perfeito: a leitura constante e repetida dos escritos clássicos, reiterando todo o ciclo de leitura desde o início; isso significava ler de verdade; apenas assim poderiam surgir resultados frutíferos, bem como o sentimento e o julgamento da arte, os quais apenas são possíveis pela compreensão do conjunto da obra de arte e da formação da mesma (SCHLEGEL 1979: 53).
}

O caráter progressivo das concepções de Fichte sobre a destinação do douto e a atividade dos diaskeuastas são alguns dos aspectos que guiam o estudioso na composição de seu conceito de crítica literária. Assim como os antigos críticos de Alexandria contribuíram para o estabelecimento dos textos homéricos, Schlegel concebe a exegese crítico-literária como uma tarefa infinita.

\section{Antigo e moderno em Schlegel e Schiller}

Na última década do século XVIII, a partir da publicação de Über naive und sentimentalische Dichtung (Poesia ingênua e poesia sentimental), de Friedrich Schiller, e dos textos de Friedrich Schlegel sobre a Antiguidade clássica, sobretudo, as obras Vom Wert des Studiums der Griechen und Römer (“Sobre o valor do estudo dos gregos 


\section{Medeiros, C. L. - O antigo e o moderno na teoria literária de F. Schlegel}

e romanos") e o Über das Studium der griechischen Poesie ("Sobre o estudo da poesia grega") tem início um grande debate a respeito da relação entre o clássico e o romântico na Alemanha. Para Hans Robert JAUSS (1970: 75), tanto o Studium-Aufsatz de Schlegel, quanto o escrito de Schiller inserem-se no gênero literário do paralelo, uma das formas literárias favoritas da tradição no que concerne à Querelle des anciens et des modernes. Na introdução que faz ao Studium-Aufsatz, Schlegel afirma que a intenção de seu escrito é levar a discussão para outro campo:

Esse ensaio Sobre o estudo da poesia grega é apenas um convite a investigar a antiga poesia de um modo mais sério do que aquele que tem sido feito até agora; uma tentativa (e ninguém será capaz de sentir os defeitos da obra de um modo mais vivo do que eu) de apaziguar o antigo conflito entre os amigos unilaterais dos poetas antigos e modernos; e, assim, através da nítida determinação dos limites no âmbito do Belo, reestabelecer a concórdia entre a formação natural e artificial (SCHLEGEL 1979: 207). ${ }^{4}$

Apesar de haver certo paralelo entre as concepções de Schiller sobre o ingênuo e o sentimental, e as ideias de Schlegel sobre o objetivo e o interessante, a origem e a intenção dos escritos de Schiller diferem substancialmente das teorizações do autor do Studium-Aufsatz. Peter SzONDI (1978: 70) afirma que os escritos sobre o poeta ingênuo e sentimental têm basicamente três razões: são uma resposta e um posicionamento em relação a Goethe, considerado um poeta ingênuo; apresentam os dois modos de fazer poético dos dois autores; ecoam as pretensões filosóficas de Schiller. Publicada na revista As Horas entre os anos 1795 e 1796, a obra de Schiller é dividida em três partes: uma sobre o poeta ingênuo, outra sobre o sentimental, e uma terceira, denominada "Conclusão do ensaio sobre os poetas ingênuos e sentimentais, com algumas observações concernentes a uma diferença característica entre os homens" (SUZUKI 1997: 9). Enquanto considerava-se um poeta sentimental, em razão da força reflexiva e do caráter subjetivo de sua poesia, Schiller avaliava que Goethe era o exemplo acabado de poeta ingênuo pela objetividade de sua criação artística. Assim, a dicotomia dos modos de fazer poético ingênuo e sentimental expõe o antagonismo entre natureza e cultura, antigo e moderno, objetivo e subjetivo, assim como a complexa relação entre a busca pelo real e o ideal na exteriorização literária. De acordo com Izabela Maria

\footnotetext{
4 "Diese Abhandlung Über das Studium der Griechischen Poesie ist nur eine Einladung, die alte Dichtkunst noch ernstlicher als bisher zu untersuzhen; ein Versuch (die Mängel desselben kann niemand lebhafter empfinden als Ich) den langen Streit der einseitigen Freunde der alten und der neuen Dichter zu schlichten, und im Gebiet des Schönen durch eine scharfe Grenzbestimmung die Eintracht zwischen der natürlichen und künstlichen Bildung wieder herzustellen“ (SCHLEGEL 1979: 207).
} 


\section{Medeiros, C. L. - O antigo e o moderno na teoria literária de F. Schlegel}

Furtado KeSTLER (2007), apesar de partirem de pressupostos análogos, Schiller e

Schlegel chegam a conclusões autônomas em suas considerações sobre a arte:

Enquanto Schiller contrapõe poesia ingênua e sentimental, antigo e moderno, natureza e cultura, com o intuito de escrutinar os modos de fazer poéticos próprios aos poetas ingênuos e aos sentimentais, Schlegel expõe a oposição entre a poesia objetiva e a interessante, entre a poesia da Antiguidade e a da Modernidade, assim como as maneiras de formação historicamente distintas da Antiguidade e da Modernidade. No plano histórico-político, as duas obras [o Studium-Aufsatz e a Poesia ingênua e sentimental] são elaboradas sob o impacto da Revolução Francesa e de seus desdobramentos. Além disso, inscrevem-se no âmbito da repercussão em território alemão da Querele des anciens et des modernes, travada na França a partir do século 17 com a publicação dos quatro volumes de Charles Perrault Parallèle des Anciens et des Modernes. E testemunham no pensamento estético alemão a influência preponderante dos estudos sobre a arte da Antiguidade clássica de Johann Joachim Winckelmann (KESTLER 2007: 9).

Friedrich Schlegel elogia a caracterização dos gêneros poéticos realizada por Schiller, mas não considera possível utilizar as tendências da criação poética para realizar a distinção entre os antigos e os modernos. Segundo o estudioso, a dicotomia entre o ingênuo e o sentimental não explica suficientemente a evolução das épocas da poesia, de modo a compreender, por exemplo, a literatura dos denominados antigos modernos, e enquadrar artistas tão complexos como Shakespeare ou Goethe, o qual era considerado ingênuo por Schiller, mas, na visão de Schlegel, é um representante da poesia romântica ou progressiva. Afirmando que o escrito de Schiller o havia influenciado em sua busca pela delimitação das épocas e das formas poéticas, Schlegel critica, todavia, o fato de que essa divisão dicotômica não leva em consideração o fato de que muitas vezes, em épocas de transição, uma natureza poética pode interpenetrar outra, até que essa passagem seja realizada completamente, como é o caso da poesia da Antiguidade tardia:

O ensaio de Schiller sobre os poetas sentimentais além de ter ampliado minha visão sobre o caráter da poesia interessante, também me deu uma nova luz sobre os limites do domínio da poesia clássica. Se eu o tivesse lido antes desse escrito ter sido enviado para publicação, especialmente o trecho sobre a origem e o caráter artístico original da poesia moderna teria ficado bem menos imperfeito. Julga-se de modo incorreto e unilateral quando se aprecia os últimos poetas da antiga arte apenas pelos fundamentos da poesia objetiva. A formação estética natural e a formação estética artificial se interpenetram, de modo que os poetas tardios da poesia antiga são, ao mesmo tempo, os precursores da poesia moderna (SCHLEGEL 1979: 209). ${ }^{5}$

\footnotetext{
5 „Schillers Abhandlung über die sentimentalen Dichter hat außer, da $\beta$ sie meine Einsicht in den Charakter der interessanten Poesie erweitere, mir selbst über die Grenzen des Gebiets der klassichen Poesie ein neues Licht gegeben. Hätte ich sie eher gelesen, als diese Schrift dem Druck übegeben war, so
} 
Medeiros, C. L. - O antigo e o moderno na teoria literária de F. Schlegel

Ainda que Schlegel indique a interpenetração desses modos poéticos de sentir e atuar, há certo paralelo entre as categorias desenvolvidas por ambos. Quanto à dialética das épocas da poesia, os pensadores têm visões aproximadas, mas não de todo semelhantes. Embora Schiller acredite que a poesia sentimental é condição fundamental para a concretização do Ideal poético, ela é ao mesmo tempo "um eterno impedimento para ele" (SCHILlER 1991: 138). Por outro lado, para Schlegel a poesia interessante era apenas uma crise passageira de gosto e conduziria novamente à representação objetiva dos antigos em uma forma futura de literatura, para a qual a arte de seu tempo apenas apontava. Entre os autores modernos que abriam esse caminho encontrava-se Goethe: "[o] caráter da cultura estética de nossa época e de nossa nação se revela mediante um notável e grande sintoma. A poesia de Goethe é a aurora da arte autêntica e da beleza pura" (SCHLEGEL 1979: 255). No que concerne à representação artística da natureza, enquanto o poeta ingênuo, em sua sensibilidade, representa artisticamente a natureza exterior, o poeta sentimental deve buscar um retorno à natureza ideal, porque, de acordo com Schiller, "o poeta é natureza ou a buscará. No primeiro caso, constitui-se o poeta ingênuo; no segundo, o poeta sentimental" (SCHILLER 1991: 60). Desse modo, a tarefa infinita que se impõe ao poeta sentimental em sua atividade reflexionante é a unificação entre a arte e a natureza no âmbito da poesia. A natureza ideal teorizada por Schiller não está em um estado passado, mas diante de nós, no futuro, como uma tarefa infinita do poeta, através da atividade reflexionante de seu espírito. Márcio SUZUKI (1991: 22) assevera que não se trata de um retorno à natureza passada, pois "não se deve de modo algum confundir a infância com a Ideia para a qual remete, nela projetando sentimentos e noções que já fazem parte da maturidade do mundo e dos homens" (SUZUKI 1991: 22). A influência dos escritos de Jean-Jacques Rousseau e de Fichte revela-se aqui não como um retorno a um estado passado, mas como busca por uma condição ideal futura, já que seria impossível retornar a um estado natural em pleno âmbito da cultura, "no seio do estado político" (SUZUKI 1991: 22):

Schiller não se cansa de chamar a atenção para o fato de que, nessa tristeza com a situação real do mundo, corre-se frequentemente o risco de tomar pela própria coisa aquilo que é apenas símbolo. É assim que se confunde o ingênuo com aquilo que

würde besonders der Abschnitt von dem Ursprunge un der ursprünglichen künstlichkeit der modernen Poesie ungleich weniger unvollkommen geworden sein. Man urteilt einseitig und ungerecht wenn man die letzten Dichter der alten Kunst bisher nur nach den Grundsätzen der objektiven Poesie. Die natürliche und die künstliche ästhetische Bildung greifen ineinander, und die Spätlinge der antike Poesie sind zugleich die Vorläufer der modernen“"(SCHLEGEL 1979: 209). 


\section{Medeiros, C. L. - O antigo e o moderno na teoria literária de F. Schlegel}

deveria representar, isto é, o verdadeiro Ideal de natureza humana. Tal é a confusão comum daqueles que, por exemplo, veem no ingênuo o próprio homem natural e que, no seio do estado político, desejam voltar ao estado de natureza. O mesmo costuma ocorrer entre aqueles que consideram a suprema perfeição estética realizada nas obras ingênuas da arte e poesia grega. Entre os poetas, esse equívoco toma corpo na ideia de uma "época de ouro" perdida. Ao mostrar que aquilo que nostalgicamente se anseia não está no passado, mas no futuro, Schiller retoma a lição de Fichte, que foi o primeiro a advertir para essa ilusão retrospectiva: Está diante de nós aquilo que Rousseau, sob o nome de estado de natureza, e os poetas, sob o nome de idade de ouro, colocam atrás de nós (SUZUKI 1991: 21).

Ao detalhar os modos de atuação da poesia sentimental, Schiller também aponta em seu escrito quais seriam os gêneros poéticos do sentimental, ou seja, a sátira, a elegia e o idílio, os quais o crítico acredita serem apenas maneiras de sentir do poeta sentimental. $\mathrm{O}$ autor afirma ainda que essas três espécies possíveis de poesia sentimental "nada têm em comum com as três espécies particulares de poema conhecidas sob esses nomes, a não ser a maneira de sentir, que é própria daqueles quanto dessas" (SCHILLER 1991: 83). Schiller aborda cada uma dessas tendências ou maneiras de sentir do poeta sentimental de acordo com a relação que estabelecem com o real e o ideal. Assim, o poeta satírico representa a contradição entre o real e o ideal: “[o] poeta é satírico, se toma como objeto o afastamento em relação à natureza e a contradição da realidade com o ideal" (SCHILLER 1991: 64). Por outro lado, o poeta elegíaco “opõe a natureza à arte e o ideal à realidade, de modo que a exposição dos primeiros predomine e a satisfação com eles se torne sensação preponderante" (SCHILLER 1991: 69). O estudioso ainda explicita a terceira categoria do sentimental, o idílio, como aquele gênero capaz de "exprimir poeticamente a humanidade inocente e feliz" (SCHILLER 1991: 83); condição esta que o autor assevera ser possível apenas no futuro: “Tal estado, porém, não se dá apenas antes do início da cultura, mas é também aquele que a cultura propõe como meta suprema, se tiver em toda parte uma tendência determinada" (SCHILLER 1991: 83). Assim, de acordo com a relação entre o real e o ideal, a sátira representa a contradição entre a realidade e o ideal; a elegia é a expressão do prazer na natureza; enquanto o idílio unifica o real e o ideal, a natureza e a arte. Em sua fundamentação da poesia romântica, universal e progressiva, Friedrich Schlegel também tem o intuito de compreender essas tendências da poesia sentimental de acordo com a relação entre o real e o ideal. Assim, buscando definir esse tipo de exteriorização literária, e realizar uma síntese filosófico-histórica dos gêneros ou tendências da poesia sentimental, o crítico afirma que: 


\title{
Medeiros, C. L. - O antigo e o moderno na teoria literária de F. Schlegel
}

Há uma poesia cujo um e tudo é a proporção entre ideal e real e que, portanto, por analogia com a linguagem técnica filosófica, teria de se chamar poesia transcendental. Começa como sátira, com a diferença absoluta entre o ideal e o real, oscila como elegia no meio, e termina como idílio, com a identidade absoluta de ambos (SCHLEGEL 1997: $88)$.

Alguns anos mais tarde, em Conversa sobre a poesia (1800), Schlegel descreve como a poesia romântica deve se concretizar no âmbito da nova mitologia, surgindo "da harmonia entre o ideal e o real" (SCHLEGEL 2016: 517). Outra aproximação entre os dois estudiosos é o entendimento de que esses modos de sentir do poeta não surgem e se estabelecem isoladamente em determinada época, mas que toda poesia pode ser composta por elementos ingênuos e sentimentais, nas mais diferentes épocas (SUZUKI 1991: 14). Em Schlegel, a concepção de que os modos de sentir e atuar da poesia natural e artificial se interpenetram transforma-se, de certo modo, no conceito de poesia romântica, universal e progressiva, ou seja, a exteriorização poética capaz de abranger tanto o espírito clássico e ingênuo quanto o espírito moderno, interessante, reflexivo e sentimental.

\section{O clássico e o romântico na teoria dos irmãos Schlegel}

\author{
Clássico e progressivo são ideias históricas \\ e intuições críticas. Nelas se reúnem a \\ crítica e a história (SCHLEGEL 2016: 182).
}

Inserida no âmbito da crítica alemã após as teorizações de Winckelmann e Herder, a compreensão histórica dos fenômenos artísticos teve como uma de suas consequências a diferenciação entre o clássico e o romântico. Embora já existissem indícios dessa classificação em autores ingleses, em solo alemão a distinção entre o clássico e o romântico foi estabelecida por Goethe e Schiller, sendo mais tarde difundida pelos irmãos Schlegel, como deixa claro o próprio Goethe nas conversas com Johann Peter Eckermann:

O conceito de poesia clássica e romântica, que atualmente corre o mundo e causa tanta polêmica e discórdia - prosseguiu Goethe - partiu originalmente de mim e de Schiller. Em poesia, eu seguia a máxima do procedimento objetivo e não reconhecia a validade de nenhum outro. Schiller, porém, que trabalhava de modo inteiramente subjetivo, considerava que esse era o procedimento correto e, a fim de se defender de mim, escreveu seu ensaio sobre a poesia ingênua e sentimental. Ele me provou que eu 


\section{Medeiros, C. L. - O antigo e o moderno na teoria literária de F. Schlegel}

mesmo, contra a minha própria vontade, era romântico, e que minha Ifigênia, graças ao predomínio do sentimento, não era de modo algum tão clássica e de acordo com os modelos antigos quanto se poderia pensar. Os Schlegel adotaram a ideia e a desenvolveram, de modo que agora ela se disseminou pelo mundo todo e todo mundo agora fala em classicismo e romantismo, nos quais ninguém pensava há cinquenta anos (ECKERMANN 2016: 392).

O estabelecimento da diferença entre a literatura clássica e a romântica contribui para a renovação dos discursos sobre a literatura ao final do século XVIII. Essa reconfiguração dos discursos da teoria, da crítica e da história da literatura somente foi possível após o desenvolvimento da consciência histórica dos fenômenos de literatura. Com as palestras e os Cursos sobre literatura bela e arte, realizadas entre os anos 1801 e 1802 por August Wilhelm Schlegel, bem como a tradução da primeira parte desses cursos com o título de Die Kunstlehre ("Doutrina da Arte") em diversas línguas, a distinção clássico/romântico torna-se definitivamente conhecida. Assim como seu irmão, August Wilhelm reconhece o grande mérito de Winckelmann e o considera o fundador da história da arte, pois através de sua contemplação da arte dos antigos como um todo orgânico estabeleceram-se novas bases para a investigação artística (SCHLEGEL 2014: 36). Na concepção de August Wilhelm, Winckelmann havia investigado a Antiguidade como um todo, mas ainda faltava delinear mais claramente a outra parte da história da literatura. A outra metade desse todo era a poesia dos modernos, que passa a ser valorizada em sua singularidade a partir da época romântica. Desse modo, se Johann Joachim Winckelmann havia fornecido os primeiros indícios de uma história sistemática da arte antiga, a tentativa de complementar essa visão histórica da literatura realizada pelos irmãos Schlegel é importante por demonstrar que era possível compreender a Antiguidade a partir de um ponto de vista que se encontrasse fora dos limites de sua atuação (SCHLEGEL 2014: 37). Assim, a divisão entre as épocas da poesia colaborou para o fortalecimento da consciência literária moderna. Ao discutir o equívoco da persistente valorização unilateral da poesia dos antigos, August Wilhelm busca compreender o conjunto da história da literatura. Em sua opinião, a visão sistemática de Winckelmann deveria ser complementada pela consciência de que, como foi dito, o todo encontrado pelo autor da História da arte da Antiguidade representava apenas uma metade da história literária:

De fundamental importância para a história da arte é o reconhecimento da oposição entre o gosto antigo e o moderno. Discutiu-se muito (particularmente pelos franceses da época de Luís XIV) sobre o privilégio dos antigos ou dos modernos, aliás imaginava-se 
Medeiros, C. L. - $\bigcirc$ antigo e o moderno na teoria literária de F. Schlegel

que eles eram apenas diferentes em grau e não segundo a espécie e que frequentemente apenas autores que se formaram inteiramente segundo a Antiguidade clássica e que procuraram avançar pelo mesmo caminho eram comparados aos antigos. Apenas recentemente foi estabelecida a afirmação, que encontra ainda muitos opositores, de que as obras que realmente marcaram época na história da poesia moderna, segundo toda sua direção e sua mais essencial aspiração, encontram-se em contraste com as obras da Antiguidade e, contudo, devem ser reconhecidas como excelentes. Designou-se o caráter da poesia antiga com a denominação de "clássico" e a moderna com a denominação de "romântico"; isso muito acertadamente, como mostrarei na sequência do desenvolvimento desses conceitos. É uma grande descoberta para a história da arte o fato de que o que se considerou até agora como a esfera inteira da arte (uma vez que se concedeu uma autoridade ilimitada aos antigos) é apenas uma única metade. A própria Antiguidade clássica pode, desse modo, ser muito mais bem compreendida do que unicamente a partir de si mesma (SCHLEGEL 2014: 36).

A consciência histórica das épocas da poesia que fundamenta os escritos dos jovens românticos, assim como sua busca pela valorização da literatura de seu tempo, encontrase implícita na afirmação de Friedrich Schlegel de que aquele que fosse capaz de traduzir de forma perfeita o clássico para o moderno "teria de dominá-lo de tal modo que fosse capaz de transformar tudo em moderno; ao mesmo tempo, deveria entender o antigo de tal modo que pudesse não só imitá-lo, mas até mesmo criá-lo novamente" (SCHLEGEl 2016: 58). Schlegel dá o nome de progressivo a essa capacidade de adaptar o antigo em roupagem moderna ou mesmo de recriá-lo. Como exemplo do que denomina ser o imperativo da progressividade, o estudioso cita o tratamento de matéria antiga realizado por Shakespeare ou Goethe (SCHLEGEL 2016: 242). A divisão entre o clássico e o romântico, realizada por ele e seu irmão, antecedeu sua teorização sobre o progressivo. Nesse sentido, expandindo a antinomia entre o antigo e o moderno, o crítico postula que há autores que são apenas clássicos, outros modernos ou românticos, ou estão em uma terceira categoria em que se incluem os progressivos, ou seja, aqueles que tratam o antigo de forma moderna. Assim, poetas (Schlegel usa "poetas" no sentido de "literatos") tão distantes no tempo quanto Petrarca, Dante, Boccaccio, Cervantes são considerados pelo estudioso como românticos, enquanto alguns artistas de seu tempo representam o exemplo de poeta progressivo, em cuja obra já se encontra entremesclada à poesia objetiva dos antigos e a poesia reflexiva dos modernos. Um desses poetas é Goethe, o qual, para Schlegel, "não era um poeta moderno mas um progressivo" (SCHLEGEL 2016: 116).

Na concepção dos irmãos Schlegel, a literatura moderna destacava-se por ser uma mistura das mais variadas formas ou gêneros literários, e por mesclar poesia e prosa, criação literária e reflexão filosófica. O desejo de compreender a poesia de seu 
Medeiros, C. L. - O antigo e o moderno na teoria literária de F. Schlegel

tempo é algo que move Schlegel desde a primeira época de sua atividade críticoliterária. Essa característica surge inclusive no mais conhecido de seus escritos, o ensaio Sobre o estudo da poesia grega. Como demonstra Ernst BEHLER (1992: 121), é sintomático que Schlegel abra essa obra com a desconcertante afirmação de que tratará mais dos modernos do que dos antigos, e que a razão para isso é que "compreender os antigos é o caminho mais curto para entender o caráter da poesia moderna" (BEHLER 1992: 121). Essa colocação de Schlegel torna-se ainda mais nítida quando se percorre o ensaio, já que grande parte do escrito é devotado à poesia dos modernos e não a dos antigos, como o próprio título parecia indicar. A meta que move Schlegel é a resolução dos problemas de seu tempo, mas o caminho que toma principia pelo conhecimento das características que fizeram da poesia dos antigos aquilo que ela foi: perfeita e acabada. Essa forma ou método de atuação, na qual ocorre a aproximação entre o antigo e o moderno, surpreende em Schlegel. Em muitas de suas obras e teorizações o estudioso trabalha a partir dessa antinomia, buscando estabelecer as bases da renovação dos estudos de literatura:

Os escritos de Friedrich Schlegel são da maior significação, tanto para a história do romantismo como para uma história geral da crítica [...] Friedrich renovou o debate sobre os antigos e os modernos, desenvolvendo daí a teoria do romântico, que a interpretação de seu irmão difundiu, literalmente, através do mundo inteiro. Mas, Friedrich não foi o autor de manifestos literários que lhe dessem unicamente uma importância histórica; foi também o autor de uma teoria crítica que antecipa muitos dos problemas prementes de nosso tempo [...] Além disso, Friedrich Schlegel expressou suas teorias de crítica, interpretação e história literária de maneira tão proveitosa que bem merece ser considerado o criador da hermenêutica, a teoria da "compreensão", a qual foi depois formulada por Schleiermacher e Boeckh e influenciou, assim, toda a longa linha de teóricos alemães da metodologia (WELLEK 1967: 5).

A importância da discussão sobre as épocas da poesia emerge no primeiro romantismo alemão como consequência da consciência histórica que os jovens românticos possuíam. No alvorecer do século XIX, a atuação dogmática e normativa do juiz de arte, o Kunstrichter, cede lugar ao crítico de arte, o Kunstkritiker. Nesse contexto de intensa alteração em todos os campos da sociedade e das artes, Friedrich Schlegel argumentava, inspirado na Revolução Francesa, que era necessário realizar uma revolução estética nos estudos de literatura. Como descrevem Philippe LACOUE-LABARTHE e Jean-Luc NANCY (2012: 35), o que surge no primeiro romantismo alemão não é uma nova forma de se fazer literatura ou teoria literária, mas a própria teoria em forma de literatura, "uma operação literária absoluta”. A partir da antinomia entre o antigo e o moderno os irmãos 
Medeiros, C. L. - $\bigcirc$ antigo e o moderno na teoria literária de F. Schlegel

Schlegel contribuíram para a renovação dos discursos da teoria, da crítica e da história da literatura.

\section{Referências bibliográficas}

BEHLER, Ernst. Einleitung. In: SCHLEGEL, Friedrich. Wissenschaft der europäischen Literatur. Padeborn: Ferdinand Schöningh, 1958. p. 3-15.

BEHLER, Ernst. Friedrich Schlegel. Schriften und Fragmente. Ein Gesamtbild seines Geistes. Stuttgart: Alfred Kröner, 1956.

BEHLER, Ernst. Frühromantik. Berlin/New York: De Gruyter, 1992.

BENJAMIN, Walter. $O$ conceito de crítica de arte no romantismo alemão. Tradução de Márcio Seligmann-Silva. São Paulo: Iluminuras, 2011.

Benne, Christian; BReUer, Ulrich. Antike - Philologie - Romantik. Friedrich Schlegels altertumswissenschaftliche Manuskripte. Paderborn: Ferdinand Schöningh, 2011.

CURTIUS, Ernst Robert. Literatura europeia e Idade Média latina. Tradução de Teodoro Cabral e Paulo Rónai. São Paulo: Hucitec/Edusp, 1996.

ECKERMAnN, Johann Peter. Conversações com Goethe nos últimos anos de sua vida. 18231832. Tradução de Mario Luiz Frungillo. São Paulo: Editora Unesp, 2016.

EICHNER, Hans (Ed.). Romantic and its cognates: The European history of a word. Manchester: Manchester University Press, 1972.

GOETHE, Johann Wolfgang. Versuch die Metamorphose der Pflanzen zu erklären. Gotha: Carl Wilhelm Ettinger, 1790.

HAYM, Rudolf. Die Romantische Schule. Ein Beitrag zur Geschichte des Deutschen Geistes. New York/Hildesheim: Georg Olms, 1977. [Reprodução da primeira edição de 1870].

HEINE, Heinrich. Die Romantische Schule. Zweites Buch. In: Düsseldorf: Artemis - Winkler, 1997. Werke III, p. 262-499.

HERDER, Johann Gottfried. Über die neue deutsche Literatur: Zweite Sammlung von Fragmenten. In: GAIER, Ulrich (Hg.). Frühe Schriften. Johann Gottfried Herder Werke. Frankfurt am Main: Deutsche Klassiker, 1985. Bd. I, p. 265-272.

JAUSS, Hans Robert. Schlegels und Schillers Replik auf die "Querelle des Ancients et des Modernes". In: Literaturgeschichte als Provokation. Frankfurt am Main: Suhrkamp, 1970. p. 67-104.

KESTLER, Izabela Maria Furtado. Friedrich Schiller X Friedrich Schlegel: confrontos e convergências em torno da fundamentação da modernidade. Encontro Regional da Abralic. Literatura, Artes e Saberes, São Paulo, 2007, p. 9. Disponível em: <www.epocadegoethe.com.br>. Acesso em: 4 maio 2017.

LABARTHE, Jean-Luc; NANCY, Philippe. El absoluto literario. Teoria de la literatura del romanticismo alemán. Buenos Aires: Eterna Cadência, 2012.

Neves, Maria Helena de Moura; Dezotte, Maria Celeste C.; Malhadas, Daisi. Dicionário Grego-Português. São Paulo: Ateliê Editorial, 2010.

SCHILler, Friedrich. Poesia ingênua e poesia sentimental. São Paulo: Iluminuras, 1997. Tradução de Márcio Suzuki.

SCHLEGEL, August Wilhelm. Die Kunstlehre. Stuttgart: W. Kohlhammer, 1963.

SCHLEgEl, August Wilhelm. Doutrina da arte. Tradução de Marco Aurélio Werle. São Paulo: Edusp, 2014. 


\section{Medeiros, C. L. - $\bigcirc$ antigo e o moderno na teoria literária de F. Schlegel}

SCHLEGEL, Friedrich. Fragmentos sobre poesia e literatura seguido de Conversa sobre poesia. Tradução de Constantino Luz de Medeiros e Márcio Suzuki. São Paulo: Editora Unesp, 2016.

SCHLEGEL, Friedrich. O dialeto dos fragmentos. Tradução de Márcio Suzuki. São Paulo: Iluminuras, 1997.

SuZUKI, Márcio. Apresentação. In: SCHILlER, Friedrich. Poesia ingênua e sentimental. São Paulo: Iluminuras, 1991. p. 9-40.

SZONDI, Peter. Das Naive ist das sentimentalische. Zur Begriffsdialektik in Schillers Abhandlung. In: Schriften-II. Frankfurt am Main: Suhrkamp, 1978. p. 59-105.

WELLEK, René. História da crítica moderna. São Paulo: Herder, 1967.

WincKelmann, Johann Joachim. Geschichte der Kunst des Altertums. Wien: Phaidon, 1934.

ZiMmERMANN, Harro. Friedrich Schlegel oder die Sehnsucht nach Deutschland. Paderborn: Ferdinand Schöningh, 2009. 